\title{
Surgical management of incomplete duplex kidney with both upper and lower moieties ureteropelvic junction obstruction: a case report with modified reconstructive method
}

\author{
Yiji Peng", Zhongyuan Zhang", Cheng Shen, Wei Yu, Gang Wang, Liqun Zhou \\ Department of Urology, Peking University First Hospital, Institute of Urology, Peking University, National Urological Cancer Center, Beijing, \\ China \\ "These authors contributed equally to this work. \\ Correspondence to: Gang Wang. Department of Urology, Peking University First Hospital, Institute of Urology, Peking University. National \\ Urological Cancer Center, No. 8 Xishiku Street, Xicheng District, Beijing 100034, China. Email: drwanggang@163.com.
}

\begin{abstract}
An incomplete duplex kidney combined with ureteropelvic junction obstruction is a rare entity, and the surgical management strategy is highly individualized according to the anatomic variability. Currently, there is no literature report of the specific reconstructive method for the condition when obstruction occurs in both the upper and lower units of the duplex kidney. In this case report, a 60-yearold female with a right solitary kidney was admitted to our hospital. The patient suffered intermittent right flank pain and had an occasionally palpable abdominal mass for seven years. Computed tomography and intravenous pyelography revealed an incomplete duplex kidney with obstruction in both the upper and lower units with a proximal confluence. A specially designed reconstructive method, including an ureteropyelostomy between the upper pole ureter and lower pole pelvis, plus a dismembered pyeloplasty between the lower pole pelvis and common ureter, was used, with no intra- or postoperative complications. The patient remained symptom free at the 6-month, 1-year and 2-year follow-ups. A diuretic renal scan showed better drainage, and ultrasound revealed no significant hydronephrosis. Thus, our specially modified reconstructive strategy could be a method of choice when addressing particular anatomies, such as incomplete duplex kidneys with ureteropelvic junction obstruction in both upper and lower poles when the obstruction is close to the confluence of the two ureters.
\end{abstract}

Keywords: Case report; duplex kidney; ureteropelvic junction obstruction; laparoscopy; genitourinary reconstruction.

Submitted Nov 04, 2020. Accepted for publication Feb 01, 2021.

doi: $10.21037 /$ tau-20-1393

View this article at: http://dx.doi.org/10.21037/tau-20-1393

\section{Introduction}

An incomplete duplex kidney is a congenital anomaly referring to the confluence of the two separate ureters localized at somewhere above the ureterovesical orifice (1). Ureteric junction obstruction (UPJO), which is another common congenital anomaly, can be associated with an incomplete duplex kidney. However, this combination is rarely observed in daily urological practice, and the surgical regimen can be difficult and complicated because of the high anatomic variability (2). Currently, the literature, such as case reports or case series, mainly focuses on the management of lower pole UPJO with incomplete duplex kidneys, while the presence of UPJO in both the upper and lower units of an incomplete duplex kidney is even rarer and there is no direct surgical strategy to address this condition. Hence, in this case report, we present a case of UPJO in both poles of an incomplete duplex kidney that occurred in an adult female with a solitary right kidney, and report a specially designed reconstructive method with two years of satisfactory outcomes. We present the following case in 

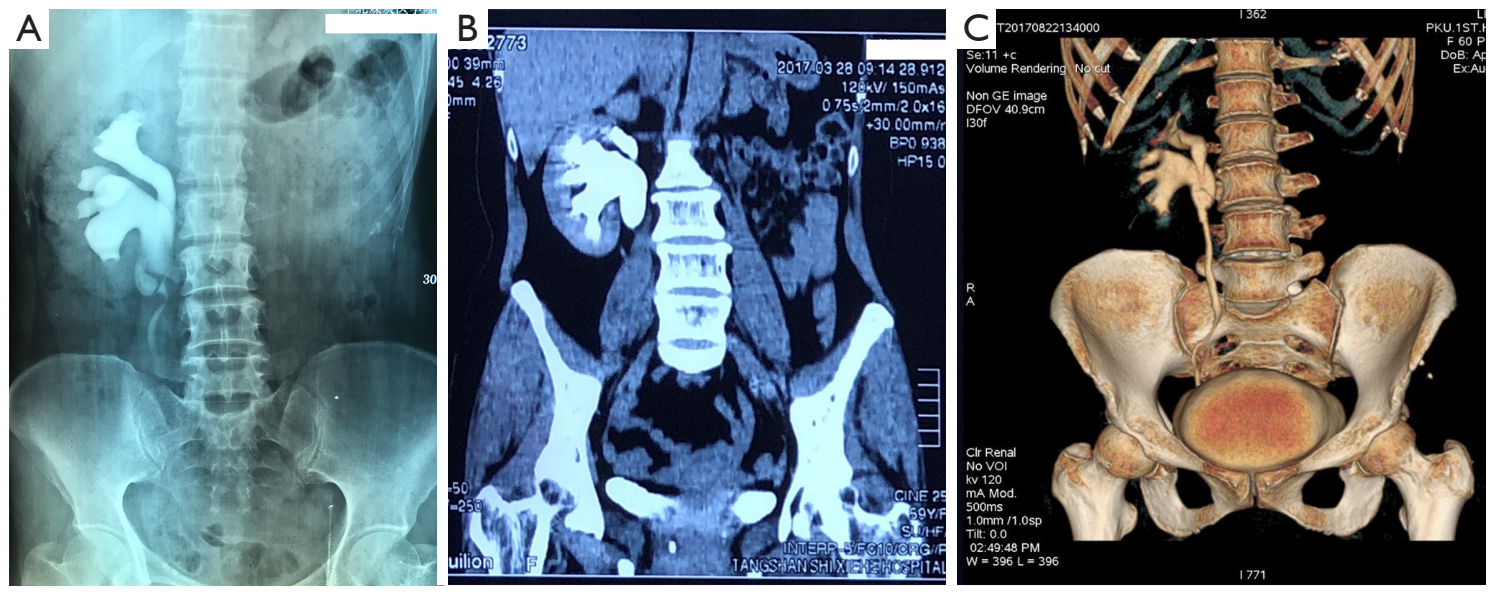

Figure 1 Preoperative intravenous pyelography (A) and preoperative CTU (B) demonstrated an incomplete duplex kidney with both upper and lower pole UPJO close to ureteral confluence. (C) Postoperative follow-up CTU revealed no significant hydronephrosis in both moieties of duplex kidney.

accordance with the CARE reporting checklist (available at http://dx.doi.org/10.21037/tau-20-1393).

\section{Case presentation}

A 60-year-old female, who had her left kidney and spleen removed because of a car accident at the age of eight, suffered intermittent right flank pain and had an occasionally palpable abdominal mass for 7 years. The symptom of right flank pain was aggravated 5 days before admission. Computed tomography and intravenous pyelography demonstrated an incomplete duplex collecting system, with the ureters joining at the level of the third lumbar vertebra and hydronephrosis of the two infundibula, indicating UPJO in both moieties of the duplex kidney (Figure 1). A ${ }^{99 \mathrm{~m}}$ Tc-DTPA diuretic renal scan revealed that the drainage of the right collecting system was impaired, with a GFR of $55 \mathrm{~mL} / \mathrm{min}$ and T1/2 over 20 minutes. A surgical intervention was indicated for this patient, considering the symptoms associated with UPJO, and compromised renal function as well as the patient's own willingness.

All procedures performed in studies involving human participants were in accordance with the ethical standards of the institutional and/or national research committee(s) and with the Helsinki Declaration (as revised in 2013). Written informed consent was obtained from the patient.

\section{Surgical technique}

A laparoscopic reconstructive procedure was performed under general anesthesia via a transperitoneal approach, and the pneumoperitoneum was established by the Veress technique. After the dissection, an incomplete duplicated collecting system was visualized as in preoperative imaging. The proximal upper pole ureter was dilated and the distal end was narrow and thin. The upper pole ureter coursed medially to the dilated lower pole pelvis and the stenotic ureteropelvic segments were close to the ureteral confluence. No crossing vessels was found (Video 1). The reconstructive procedure was arranged in two parts and is demonstrated in Figure 2 and Video 1. The first part was an ureteropyelostomy to join the upper pole ureter and lower pole pelvis together by excising the stenotic distal part of the upper pole ureter. The second part was a standard dismembered pyeloplasty performed by excising the narrow segment in the lower moiety and ureteral confluence. During the reconstructive procedure, a double J stent was inserted to the collecting system with its upper end in the upper-moiety ureter and lower end in the bladder. The surgery was performed by a surgeon with 150 successful urological reconstructive experience.

\section{Results}

The blood loss was minimal. The total operative time was 

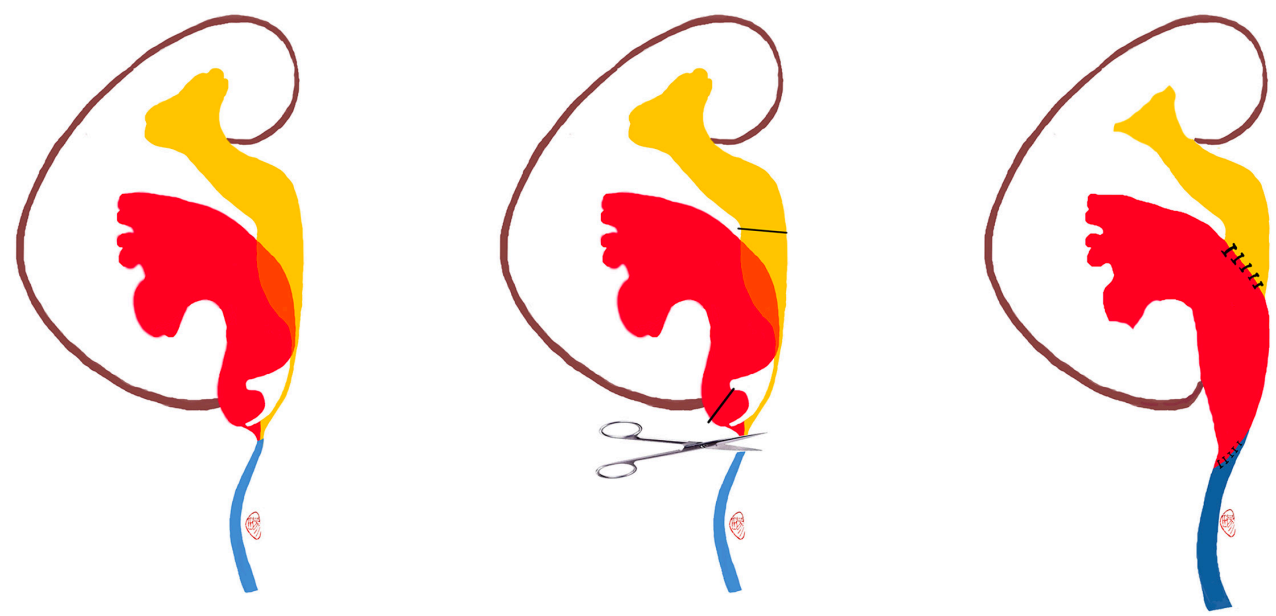

Figure 2 Descriptive diagram of the specially designed reconstructive procedure.

262 minutes. The postoperative course was uneventful, and the patient was discharged on postoperative day 6 . The double-J stent was removed 6 weeks after the operation at the outpatient department. At the 3-month follow-up, a diuretic renal scan revealed a GFR of $85 \mathrm{~mL} / \mathrm{min}$, with prompt drainage without obstruction of the right solitary kidney (T1/2 12.39 minutes), and computed tomography demonstrated no significant hydronephrosis in either moiety of the duplex kidney (Figure 1C). The patient remained symptom free at the 6-month, 1-year and 2-year follow up and ultrasound revealed no significant hydronephrosis.

\section{Discussion}

The duplicated collecting system is a congenital urological anomaly due to the disrupted integration between the Wolffian duct and the metanephrons. Normally, a single ureteric bud arises from the Wolffian duct and migrates to meet the metanephrons, then the former bifurcate sequentially to form the renal collecting system and the latter evolve into the renal parenchyma. Specially, when the single ureteric bud bifurcates prior to meet the metanephrons, the incomplete duplicated kidney was developed (1). The incidence of duplicated collecting system was $0.5-0.8 \%$ (3). Larger series have reported an incidence of $2-7 \%$ of UPJO in duplex kidneys (4). Obstruction occurs more often in the lower pole ureter. Rubenwolf $e t$ al. showed that the upper moiety was affected in 13\% (14/111) of patients and lower moiety was affected in 87\% (97/111) of patients because the lower moiety usually drained a large part of the parenchyma and the upper pole was merely an infundibulum without a true renal pelvis (2). Our case was unique in that obstruction occurred in both the upper and lower moieties of a duplex kidney, and as our research showed, no such report had been previously published. In addition, the patient developed symptoms in her right solitary kidney at the age of 53 , which is uncommon in the natural history of congenital diseases.

Treatment of UPJO in duplex kidneys should follow guidelines similar to those used for single-system UPJO, and surgical intervention has been suggested for patients with recurrent symptoms, asymptomatic UPJO associated with relevant obstruction and impaired function of the affected renal moiety, and failure of conservative management. In this case, the patient presented with symptoms and compromised renal function in her solitary kidney and was indicated for surgery. The surgical regimen for UPJO in duplex kidneys has been tailored to a particular anatomy of the collecting system, and surgical options are an excision of the stenotic segment using a dismembered pyeloplasty or ureteropyelostomy/pyelopyelostomy, depending on whether the duplication is complete or incomplete and on the site of the ureteral confluence and the main purpose is to excise the adynamic segment of the ureter and achieve better 
drainage $(2,5,6)$. For the most prevalent type of anomaly, the lower pole UPJO close to the confluence in incomplete duplicated systems, an end-to-side pyeloureterostomy is commonly performed. In this case, based on preoperative imaging and intraoperative findings, the obstruction was significant in the lower pole ureter of the duplex kidney. There also was hydronephrosis in the upper moiety, and the upper pole ureter was narrow and thin, which might have been secondary to the dilated lower pole pelvis or due to a primary ureteral stricture. The confluence of the two ureters was close to the obstruction site. In this situation, an end-to-site pyeloureterostomy could be an option, however, since the potential resected ureter should involve the stenotic distal part of both the upper and lower pole ureters, an end-to-side pyeloureterostomy was not regarded as an ideal choice because of the higher surgical difficulty and an increased risk for anastomotic restricture. To optimize the reconstructive procedure, we replaced the complicated end-to-side pyeloureterostomy with an ureteropyelostomy plus a standard AndersonHynes pyeloplasty, which are both frequently performed as urological routines. Moreover, the dilated upper and lower pole pelvis provided enough material to accomplish an anastomosis without tension. There were no intraor postoperative complications related to the surgery, and after a two-year follow-up, the patient remained symptom free. Furthermore, an imaging study revealed no significant hydronephrosis in the collecting system. Therefore, this specially designed reconstructive method could be deemed successful in this patient.

\section{Conclusions}

In conclusion, our specially designed reconstructive strategy could be a method of choice when dealing with particular anatomies, such as incomplete duplex kidneys with UPJO in both upper and lower poles when the obstruction is close to the confluence of the two ureters.

\section{Acknowledgments}

Funding: None.

\section{Footnote}

Reporting Checklist: The authors have completed the CARE reporting checklist. Available at http://dx.doi.org/10.21037/ tau-20-1393

Peer Review File: Available at http://dx.doi.org/10.21037/ tau-20-1393

Conflicts of Interest: All authors have completed the ICMJE uniform disclosure form (available at http://dx.doi. org/10.21037/tau-20-1393). The authors have no conflicts of interest to declare.

Ethical Statement: The authors are accountable for all aspects of the work in ensuring that questions related to the accuracy or integrity of any part of the work are appropriately investigated and resolved. All procedures performed in studies involving human participants were in accordance with the ethical standards of the institutional and/or national research committee(s) and with the Helsinki Declaration (as revised in 2013). Written informed consent was obtained from the patient.

Open Access Statement: This is an Open Access article distributed in accordance with the Creative Commons Attribution-NonCommercial-NoDerivs 4.0 International License (CC BY-NC-ND 4.0), which permits the noncommercial replication and distribution of the article with the strict proviso that no changes or edits are made and the original work is properly cited (including links to both the formal publication through the relevant DOI and the license). See: https://creativecommons.org/licenses/by-nc-nd/4.0/.

\section{References}

1. Didier RA, Chow JS, Kwatra NS, et al. The duplicated collecting system of the urinary tract: embryology, imaging appearances and clinical considerations. Pediatr Radiol 2017;47:1526-38.

2. Rubenwolf P, Ziesel C, Beetz R, et al. Presentation, Management and Long-Term Outcome of Ureteropelvic Junction Obstruction in Duplex Kidneys. J Urol 2015;194:427-32.

3. Modi P, Goel R, Rizvi SJ. Case report: laparoscopic pyeloplasty for ureteropelvic junction obstruction of lower moiety in duplex system. J Endourol 2007;21:1037-40.

4. Horst M, Smith GH. Pelvi-ureteric junction obstruction in duplex kidneys. BJU Int 2008;101:1580-4.

5. Liu W, Zhang L, Ma R, et al. The morphology and 
treatment of coexisting ureteropelvic junction obstruction in lower moiety of duplex kidney. Int J Surg 2016;34:23-7.

6. Avlan D, Gündoğdu G, Delibaş A, et al. Pyeloureterostomy in the management of the lower pole pelvi-ureteric junction obstruction in incomplete duplicated systems. Urology 2010;76:1468-71.

Cite this article as: Peng $\mathrm{Y}$, Zhang Z, Shen $\mathrm{C}$, Yu W, Wang G, Zhou L. Surgical management of incomplete duplex kidney with both upper and lower moieties ureteropelvic junction obstruction: a case report with modified reconstructive method. Transl Androl Urol 2021;10(4):1792-1796. doi: 10.21037/tau-201393 